MR. ANDY DURHAM (Orcid ID : 0000-0002-5420-1102)

3

4

Article type : Editorial

6

7

8

9

10

EVJ-ED-17-040.R1

11 Science in brief: Workshop Report

12 The Dorothy Havemeyer International Equine Endocrinology Summit

13

14

Durham, A.E., Bailey, S.R. ${ }^{1}$, Frank, N. ${ }^{2}$, McFarlane, D. ${ }^{3}$, Schott, H.C. ${ }^{4}$ and Paradis, M.R. ${ }^{2}$

15

Liphook Equine Hospital, Liphook, Hampshire, UK; ${ }^{1}$ The University of Melbourne, Australia; ${ }^{2}$ Cummings

16

School of Veterinary Medicine, Tufts University, North Grafton, Massachusetts, USA; ${ }^{3}$ Oklahoma State

17 University, Physiological Sciences, 264 McElroy, Stillwater, Oklahoma 74074, USA; ${ }^{4}$ Michigan State

University College of Veterinary Medicine, East Lansing, Michigan 48824-1314, USA.

19

The Dorothy Havemeyer International Equine Endocrinology Summit 2017 was held between 3-7

21 January 2017 in Coral Gables, Florida with the generous support of Boehringer-Ingelheim Vetmedica.

22 There were 52 attendees from 7 countries and 3 continents that delivered 36 oral research 23 presentations and 14 summary oral/poster presentations covering a wide range of endocrine disorders 24 with focus areas of Pituitary Pars Intermedia Dysfunction (PPID), Equine Metabolic Syndrome (EMS) and

25 Insulin Dysregulation (ID). Liberal discussion periods followed each session allowing all delegates to

This is the author manuscript accepted for publication and has undergone full peer review but has not been through the copyediting, typesetting, pagination and proofreading process, which may lead to differences between this version and the Version of Record. Please cite this article as doi: $\underline{10.1111 / e v j .12686}$

This article is protected by copyright. All rights reserved 
question and comment further on the studies presented. This workshop summary presents a brief

27 overview of the topics discussed.

\section{Pathophysiology and Diagnostics} James Carmalt (Western University, Canada) presented work using real time PCR to demonstrate that proopiomelanocortin, prohormone convertase 1 and prohormone convertase 2 expression are all increased in the pituitary gland of horses with PPID, compared with younger control horses. He further reported on novel housekeeping genes that can be used to assess relative expression of genes of interest. Han van der Kolk (University of Bern, Switzerland) presented novel data comparing plasma ACTH concentrations in blood samples collected simultaneously from the cavernous sinus surrounding the pituitary gland and the jugular vein providing evidence that a degree of neuronal regulation may persist in the pars intermedia of PPID-affected equids. Andy Durham (Liphook Equine Hospital, UK) examined the relationship between seasonal changes in plasma ACTH concentrations and day length in nearly 150,000 laboratory ACTH submissions and showed that the ACTH response to TRH stimulation followed a similar pattern of magnified response to long days and suppression from short days. The possibilities of light manipulation of pituitary activity was discussed. Data from nearly 60,000 plasma samples from PPID and non-PPID horses showed an association between plasma ACTH and age throughout the year. Breed, colour and sex effects on plasma ACTH were also found but only in the autumn months. The importance of signalment in interpretation of test results was a common theme of discussion throughout the Summit and Ramiro Toribio (Ohio State University, USA) shared preliminary data indicating that endocrine test reference intervals for horses may not be valid in donkeys while Dianne McFarlane (Oklahoma State University, USA) reported a higher ACTH upper cutoff limit in older horses than is generally applied. Geographic influences on ACTH secretion were described by Rachel Tan (James Cook University, Australia) and Cristy Secombe (Murdock University, Australia) who found that horses residing closer to the equator (those exposed to a smaller magnitude of change in day length) demonstrated a smaller seasonal effect on pars intermedia activity. These researchers also suggested a magnified ACTH response to TRH stimulation test in horses without clinical signs of PPID in the autumn months. This was also supported by work performed by Amanda Adams and colleagues (University of Kentucky, USA) who provided an indication of the magnitude and variation of normal ACTH responses to TRH through the whole year. Anna Chapman (Louisiana State University, USA) and Kerstin Fey

57 (University of Giessen, Germany) both presented studies indicating that lower doses of TRH appeared as 
effective as the standard $1 \mathrm{mg}$ dose, although testing of a larger number of horses would be warranted before a change in the current testing protocol could be recommended. Edd Knowles (Royal Veterinary College, UK) compared performance characteristics of two ACTH assays validated in the horse: the chemiluminescent immunoassay (Immulite) and a fluorescent immunoenzymometric assay (AIA 360). Interestingly, a disparity was found in assay results in the autumn suggesting some cross reactivity of the chemiluminescent assay with other pituitary peptides that might prove useful diagnostically. In the ongoing quest to find novel screening tests to identify earlier stages of PPID, Hal Schott (Michigan State University, USA) reported that serum prolactin concentration was greater in horses with PPID than in normal horses and Dianne McFarlane described a proteomic approach to identify peptide signatures for PPID in equine plasma using MALDI-TOF mass spectrometry. Ruth Morgan (University of Edinburgh, UK) reported that urinary, but not plasma, androgens differed between normal horses and those with EMS or PPID.

Equine Metabolic Syndrome

Samantha Brooks (University of Florida, USA) used high-performance liquid chromatography-mass spectrometry to identify several features correlating with EMS, although the nature, origin and relevance of these features has yet to be established. Martin Sillence (Queensland University of Technology, Australia) showed that insulin response to a high starch challenge diet was inversely related to the time taken to develop laminitis, supporting the value of oral carbohydrate challenge tests in predicting laminitis risk. Nicola-Menzies Gow (Royal Veterinary College, UK) re-evaluated the Karo Light Syrup-based oral sugar test (OST) [1] and found that a higher syrup dose than is generally used better differentiated ponies with and without a history of laminitis although test results could vary within individual ponies through the year. The test could be performed with or without prior fasting without affecting results. Dianne McFarlane's group evaluated possible mechanisms explaining hyperinsulinaemic laminitis and found only minor effects of an IGF-1 receptor antagonist on hyperinsulinaemia-induced laminitis. Several groups scrutinised the usefulness of the combined glucose/insulin test (CGIT) [2] with Caroline Argo (University of Surrey, UK) reporting that the CGIT was useful in predicting resistance to early weight loss during dietary restriction in ponies. However, other studies illustrated limitations of the CGIT with Pat Harris (Mars Horsecare, UK) questioning the interpretative criteria of the CGIT in ponies and Alex Dugdale and colleagues (University of Liverpool, UK) finding only some, but not other, measures of body fat mass were related to CGIT results. Cathy McGowan and coworkers (University of Liverpool, UK) compared the sensitivity and specificity of fasted basal insulin with CGIT values in horses and ponies 
with suspected endocrine disease and found limitations in the use of fasting values using conventional cut-offs. Ellen Roelfsema (Utrecht University, Netherlands) provided further evidence of the individual variability in insulin responses to weight gain in ponies. Molly McCue (University of Minnesota, USA) gave an overview of 'Big Data' approaches to EMS, summarising the various studies that her group are currently undertaking including studies at the genomics, transcriptomics and metabolomics levels. Based on morphometric, biochemical and hormonal phenotypes, several chromosomal regions and candidate genes have been identified which are associated with various traits linked to EMS, as well as indications of some novel metabolic differences between hyper- and normo-insulinaemic animals. This overview was followed by three further presentations from the same University of Minnesota group focusing on each of the key areas of research. Jane Manfredi described breed specific patterns of differentially expressed genes that may contribute to insulin dysregulation and Elaine Norton presented work identifying a genetic locus associated with height and fasting insulin, mainly in Welsh ponies. Sian Durward-Akhurst showed that the majority (but not all) of the variance in phenotypes related to EMS could be explained by individual factors including; signalment, obesity, laminitis history, body morphology, genetics, diet and exercise. However in many cases other environmental factors were also deemed to play a role.

\section{Insulin Dysregulation}

107 Nick Frank (Tufts University, USA) performed an immunohistochemical study of pancreatic islets in insulin resistant and normal horses and found differences in the area staining for glucagon but not insulin or somatostatin. Kelsey Hart (University of Georgia, USA) presented a pilot study showing differences in insulin, ACTH and free, but not total, cortisol when comparing normal and insulindyregulated horses and ponies. Melody de Laat (Queensland University of Technology, Australia) 112 presented work confirming the presence and activity of the incretins, gastric inhibitory peptide (GIP) and 113 glucagon-like peptide 1 (GLP-1) receptors in pancreatic tissues. Simon Bailey and colleagues (University of Melbourne, Australia) compared post-prandial plasma concentrations of GIP in horses and ponies of 116 hyperinsulinaemia.

117 Edd Knowles (Royal Veterinary College, UK) and Tobias Warnken (University of Veterinary Medicine 118 Hannover, Germany) both compared different insulin assays and showed the Immulite 119 chemiluminescent immunoassay to yield lower insulin values than radioimmunoassay and ELISA 120 methods, especially at low serum insulin concentrations, emphasising the need to take method into 121 account when comparing insulin data from different laboratories. Janice Kritchevsky (Purdue University, 
122 USA) described the effects of xylazine or detomidine on serum insulin emphasising the need for caution

123 when interpreting endocrine test results in recently sedated horses.

124 Frank Andrews (Louisiana State University, USA) investigated colonic transport and barrier function in 125 insulin resistant horses at low pH illustrating possible effects of feeding diets high in non-structural 126 carbohydrates to such horses. Sarah Elzinger (University of Kentucky, USA) explored the association of 127 insulin dysregulation (ID) and inflammation by examining the inflammatory and insulinaemic effects of 128 an OST. Dr Elzinger also described how oral docosahexaenoic acid (DHA, Omega-3 fatty acid) 129 supplementation demonstrated some beneficial effects on inflammation and ID.

130 Anne Wooldridge (Auburn University, USA) described the effects of mild to severe clinical disease on 131 HMW adiponectin concentrations showing a decrease only in mild to moderate illness. Critical illness 132 was also the focus for Ramiro Toribio (Ohio State University, USA) who examined the relationship 133 between markers of bone metabolism and insulin in hospitalised foals. The findings suggested a possible 134 impairment of the osteoblast insulin signaling, reflecting a possible sepsis-mediated IR.

\section{Epidemiology}

136 Two epidemiological studies were presented by Michelle Coleman (Texas A \& M University, USA) and Melody de Laat (Queensland University of Technology, Australia) examining risk factors for laminitis. The US study attributed significant laminitis risk both to markers of obesity and exogenous and endogenous endocrine factors with the latter being supported by evidence from the Australian study also. Melody de 140 Laat described how dietary modification was commonly recommended but many laminitis cases recurred nevertheless. A presentation by Steve Grubbs (Boehringer-Ingelheim Vetmedica, USA) investigated clinical signs of PPID in a group of mature sport horses and introduced the novel finding of suspensory ligament desmitis and superficial digital flexor tendonitis as possible consequences of PPID.

144 Pharmacology

145 Nicole Arana-Valencia and colleagues (Louisiana State University, USA) examined possible dopaminergic 146 mechanisms in pharmacologic manipulation of insulin sensitivity in the horse but failed to find any evidence of such. David Rendle (Charles Sturt University, Australia) reported pharmacokinetics and pharmacodynamics of oral pergolide suggesting a fairly rapid onset of action. Previous studies on metformin have yielded mixed results [3-6] and John-Pierre Lavoie (Université de Montréal, Canada) presented a blinded trial in which metformin decreased body weight and the owner's assessment of overall condition, but did not significantly alter glucose and insulin values.

152 The meeting concluded with further discussion and plans for early dissemination of the new findings 153 presented at the meeting via this current article, online access to the meeting proceedings [7] and 
154 future updated consensus statements from panels appointed by the American College of veterinary 155 Internal Medicine and European College of Equine Internal Medicine.

\section{References}

159 [1] Schuver, A., Frank, N., Chameroy, K.A. and Elliott, S.B. (2014) Assessment of Insulin and Glucose 160

[2] Eiler, H., Frank, N., Andrews, F.M., Oliver, J.W. and Fecteau, K.A. (2005) Physiologic assessment

[3] Durham, A.E., Rendle, D.I. and Newton, J.E. (2008) The effect of metformin on measurements of 165

[5] Rendle, D.I., Rutledge, F., Hughes, K.J., Heller, J. and Durham, A.E. (2013) Effects of metformin hydrochloride on blood glucose and insulin responses to oral dextrose in horses. Equine Vet. J.

\section{2} Rendle, D.I., Rutledge, F., Hughes, K.
hydrochloride on blood glucose and
45, 751-754. doi: 10.1111/evj.12068 insulin sensitivity and beta cell response in 18 horses and ponies with insulin resistance. Equine Vet. J. 40, 493-500.

[4] Hustace, J.L., Firshman, A.M. and Mata, J.E. (2009) Pharmacokinetics and bioavailability of metformin in horses. Am. J. Vet. Res. 70, 665-668.

[6] Tinworth, K.D., Boston, R.C., Harris, P.A., Sillence, M.N., Raidal, S.L. and Noble, G.K. (2012) The effect of oral metformin on insulin sensitivity in insulin-resistant ponies. Vet. J. 191, 79-84.

[7] http://sites.tufts.edu/equineendogroup/

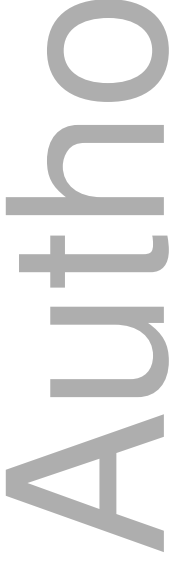




\section{University Library}

\section{- M M I N E R VA \\ A gateway to Melbourne's research publications}

Minerva Access is the Institutional Repository of The University of Melbourne

Author/s:

Durham, AE;Bailey, SR;Frank, N;McFarlane, D;Schott, HC;Paradis, MR

Title:

Science-in-brief: Workshop report The Dorothy Havemeyer International Equine Endocrinology Summit

Date:

2017-07-01

Citation:

Durham, A. E., Bailey, S. R., Frank, N., McFarlane, D., Schott, H. C. \& Paradis, M. R. (2017). Science-in-brief: Workshop report The Dorothy Havemeyer International Equine Endocrinology Summit. EQUINE VETERINARY JOURNAL, 49 (4), pp.408-409. https:// doi.org/10.1111/evj.12686.

Persistent Link:

http://hdl.handle.net/11343/293019 